\title{
Pathomorphological Alterations in Various Organs of Experimentally Induced Listeriosis in Mice
}

\author{
M.A. Malik ${ }^{1}$, J.K. Sharma ${ }^{2}$, Moien Javaid ${ }^{*}$, Maninder Singh ${ }^{1}$ and Raghubir Singh ${ }^{1}$ \\ ${ }^{1}$ Division of Veterinary Public Health and Epidemiology, F.V.Sc \& A.H., R.S.Pura, \\ Jammu, SKUAST-J, India \\ ${ }^{2}$ Department of Veterinary Public Health and Epidemiology, GADVASU, \\ Ludhiana, Punjab, India \\ *Corresponding author
}

\begin{tabular}{|c|c|}
\hline & B S T R A C T \\
\hline & \multirow{7}{*}{$\begin{array}{l}\text { Listeria monocytogenes isolates were intraperitoneally administered into the mice to } \\
\text { evaluate the histopathological changes in various organs of the infected mice. The study } \\
\text { consisted of nine groups of mice each group comprising of three mice. Inocula prepared } \\
\text { from seven different isolates of Listeria monocytogenes were administered into seven } \\
\text { different groups. The study also included one positive control (inoculated with reference } \\
\text { strain) and one negative control (inoculated with normal saline) groups. The total period of } \\
\text { study was } 10 \text { days. The pathogenicity of isolates and the reference strain was studied by } \\
\text { injecting a fixed dose of organisms intraperitoneally into mice. The death of mice occurred } \\
\text { between } 2^{\text {nd }} \text { to } 6^{\text {th }} \text { post exposure day. Four isolates killed more than } 50 \% \text { of mice, two } \\
\text { isolates killed more than } 30 \% \text { of mice where as one isolate caused no death. The } \\
\text { histopathological examination revealed more severe changes in liver and included } \\
\text { microabscesses. The section of kidneys of infected mice revealed mild focal vacuolar } \\
\text { degeneration in cortical epithelial cells. The sections of spleen, myocardium and brain also } \\
\text { revealed altered histopathogical changes. }\end{array}$} \\
\hline Keywords & \\
\hline & \\
\hline & \\
\hline & \\
\hline Article Info & \\
\hline $\begin{array}{l}\text { Accepted: } \\
\text { 10 October } 2017 \\
\text { Available Online: } \\
10 \text { December } 2017\end{array}$ & \\
\hline
\end{tabular}

\section{Introduction}

Food and food products contaminated with food borne pathogens often look and smell the same as safe food, thus mere visual inspection is not enough to ensure safety of such food ingredients. Laboratory-based surveillance of animals, food and humans becomes necessary to detect and prevent food borne pathogens from entering or spreading through the food chain, besides assisting in appropriate control measures. Many countries including India, still lack the necessary surveillance capacity for outbreak detection and response, thus food borne disease outbreaks often go undetected.
Due to the globalization of animal and food trade, national food safety issues can have global implications. Amongst food borne pathogens, Listeria is important cause of food borne disease in humans and domestic animals. In human beings, it affects pregnant women, their fetuses, and neonates and may cause abortions, still births and neonatal sepsis. In farmers and veterinarians, cutaneous listeriosis has also been reported (Mclauchlin and Low, 1994). In animals, it causes encephalitis, abortions and septiceamia or occasionally spinal myelitis or 
keratoconjunctivitis. The genus Listeria consists of a group of Gram-positive bacteria closely related to Bacillus, Clostridium, Enterococcus, Streptococcus and Staphylococcus. Listeria spp. Are facultative anaerobic rods of 0.4 by 1 to $1.5 \mathrm{~mm}$ that do not form spores, have no capsule, and are motile at 10 to $25^{\circ} \mathrm{C}$ (Rocourt, 1999).

Listeria monocytogenes is more likely to contaminate the environment through faeces, urine and secretions such as conjunctival, oral, nasal and uterine fluid of carriers. Wild birds and roof rats can harbor this organism and therefore, contaminate the environment through their faeces. In ruminants, it is often transmitted through contaminated silage and from animal to man, it is transmitted through meat, milk, and via disposal of waste products to the land.

Listeria infection arising from contaminated food continues to be an immense problem with millions of cases occurring annually throughout the world, detection of Listeria before contaminated foods can be consumed is therefore an essential feature of safeguarding public health. Surveillance of Listeria in all the different stages of food chain constitutes an important element in the exploration of epidemiology of food borne listeriosis, and in the development and implementation of efficient Listeria control strategies. The growth characteristics and its ubiquitous distribution make it ideal for transmission through food specially as post process contaminant of refrigerated food.

For a long time, mice and to a smaller extent rats were the most popular species used to establish models of listeriosis, particularly evaluating septicemic death (Lecuit, 2007). The development of invasive disease in these animals is dose dependent, but in adult animals relatively high doses are often required to induce disease and death (Lecuit,
2007). Despite these drawbacks, mice and rat models have proved instrumental in demonstrating key aspects of $L$. monocytogenes infection and immunity. The clinical disease in otherwise healthy individuals varied from a mild, self-limiting gastroenteritis to more severe systemic and intestinal infections that even required hospitalization. L. monocytogenes infections in immune compromised individuals, including both the elderly and neonates, have been linked with a high mortality rate (25$30 \%$ ), even after antibiotic treatment (Wing et al., 2002). Very little is known about the infectious dose for L. monocytogenes, or the host factors that dictate the susceptibility to infection after oral transmission, primarily due to the lack of a small animal model that recapitulates this wide range of infection outcomes. The most widely used model of listeriosis is intravenous (i.v.) inoculation of mice. The i.v. model is highly reproducible, and has been considerably useful for studying both naïve and memory $\mathrm{T}$ cell responses during infection (Condotta et al., 2012). The limitations of the i.v. model are that it completely bypasses the intestinal phase of infection. After food borne transmission, the gut mucosa presents a barrier that apparently slows and limits the quantum of bacteria that can continually disseminate to peripheral tissues. In contrast, the whole inoculum can be found in the spleen and liver within minutes of i.v. administration, and this large quantum of organisms may overwhelm innate immune responses in these tissues. Oral infection of mice by gavage is less commonly used, because large doses $\left(10^{9}-10^{11} \mathrm{CFU}\right)$ are typically required to obtain intestinal colonization (Disson, 2009). Also, intragastric (i.g.) inoculation with a feeding needle does not generate a reproducible period of gastrointestinal infection prior to systemic spread. Some researchers have reported that L. monocytogenes reach the spleen and liver within 4-12 hours post infection (hpi), while 
others showed no systemic spread until 48 hpi (Gajendran, 2007). Although the i.g. route provides more control over dose, it may have some adverse consequences. First, when $L$. monocytogenes are administered in a liquid suspension, the majority of the bacteria transit quickly through the gut, and are shed in stool within 0.25 to 4 hours (Hardy et al., 2004; Melton-Witt et al., 2012). Rapid passage may not allow enough exposure to the acidic $\mathrm{pH}$ and bile present in the upper gastrointestinal tract for induction of the transcriptional changes that make L. monocytogenes more invasive in the gut (Conte et al., 2000). In order to overcome these drawbacks, in our study we used intraperitonial route for introducing infection in mice. Keeping in view these facts, the present study was carried out with the aim to evaluate the patho-morphological changes in experimentally induced listeriosis in the small animal model "mice".

\section{Materials and Methods}

\section{Experimental animals}

Apparently healthy 27 white mice were procured from the Department of Zoology, PAU, Ludhiana and randomly divided into nine equal groups (group I to IX) having three mice in each. The animals were housed in under specific pathogen free conditions in polypropylene cages with free access to sterilized pelleted feed and water ad libitum. A daily cycle of 12 hours of light and similar 12 hours of darkness was provided to animals. The permission from institutional animal ethics committee was obtained to conduct the experimentation.

\section{Pathogenicity of Listeria infection}

Pathogenicity of Listeria monocytogenes infection in mice was studied as per method of Menudier et al., (1991). Reference strain and seven isolates were cultured in Brain
Heart Infusion broth (Himedia, M-211) and incubated at $35^{\circ} \mathrm{C}$ for 18 hours. The bacterial cells were centrifuged at $3000 \mathrm{rpm}$ for 15 minutes. The supernatant was removed aseptically and bacterial cells were suspended and reconstituted in physiological saline. The inoculum was adjusted to $10^{6} \mathrm{CFU} /$ per mouse by intraperitoneal route (Takeuchi et al., 2006; Xiong et al., 1994). After 48 hours of acclimatization, seven groups were administered with inocula prepared from seven isolates, with one isolate in each group. Two groups were kept as control, one positive control and other negative control. In positive control inoculums from reference strain was injected while in negative control, $0.5 \mathrm{ml}$ of normal saline was injected intraperitoneally in to each mouse. The experiment was carried out for 10 days during which symptoms exhibited by the mice were observed and deaths were recorded.

\section{Histopathological changes}

Postmortem of the dead mice was carried out and gross and histopathological changes were noted in liver, spleen, kidney, brain, heart, and lungs. Cultural examination of organs was also done. At the end of the trial, the surviving animals were sacrificed by cervical dislocation and their organs were collected for histopathological examination. For histopathology, the organs were fixed in $10 \%$ $(\mathrm{v} / \mathrm{v})$ neutral buffered formalin solution. After 3-4 days of fixation, tissues were washed in running water for 7-8 hrs, dehydrated in ascending grades of ethyl alcohol, cleared in benzene and embedded with melted paraffin wax (melting point $58^{\circ} \mathrm{C}$ ). The paraffin blocks were prepared and sections were cut at $4-5 \mu$ thickness with a hand operated microtome. The paraffin embedded sections were then passed through sequential steps of deparaffinisation in xylene, rehydration by passing through descending grades of ethyl alcohol to running tap water and stained with 
routine haematoxylin and eosin stain (H\&E) as per method of Luna (1968).

\section{Results and Discussion}

Generally $24 \mathrm{hrs}$ after administration of inocula, some mice in each group were lethargic and withdrawn. Few appeared severely ill and deaths occurred between $2^{\text {nd }}$ to $6^{\text {th }}$ day post exposure. In group I, II, IV and $\mathrm{V}$ two deaths each were recorded, one death each was recorded in group III and VI, whereas no death was recorded in group VII and negative control. In positive control, two deaths were recorded.

At necropsy, gross lesions of moderate to severe focal hepatic necrosis characteristic of listeric septicaemia were observed. In some cases, brain and spleen were congested. No significant gross lesions were observed in heart, lungs and kidneys. Listeria monocytogenes was isolated from liver, spleen and brain of mice that died.

Surviving mice were sacrificed on $10^{\text {th }}$ day post- exposure, three of these had necrotic foci on the liver and Listeria monocytogenes was isolated from all of these mice. Gram positive rods were demonstrated in the impression smears of liver and brain from the dead mice.

Histopathological examination revealed more severe changes in liver and included microabscesses with degenerated and intact neutrophils and mild infiltration of mononuclear cell (Plate 1). Microabscesses were also observed in perivenular area. Liver of some mice showed hyperplasia of Kupfer cells and granuloma formation due to mononuclear cell infiltration (Plate 2). Gram staining of tissue section revealed Gram positive rods (Plate 3). Histopathology sections of the liver showed hepatocyte necrosis with infiltration of degenerative neutrophils, lymphocytes and few plasma cells compared to control as was also reported by Enurah et al., (2013). During the early steps of liver colonization, polymorphonuclear neutrophils are recruited at the sites of infection, forming discrete microabscesses. Neutrophils have been shown to play an important role in controlling the acute phase of Listeria infection (Rogers and Unanue, 1993) and in mediating the destruction of Listeria infected hepatocytes in vivo (Conlan and North, 1991). Hepatocytes respond to Listeria infection by releasing neutrophil chemoattractants and exhibiting an increase in adhesion to neutrophils, resulting in microabscess formation (Rogers et al., 1996).

Section of kidneys of infected mice revealed mild focal vacuolar degeneration of cortical epithelial cells (Plate 4) and subcapsular infiltration of mononuclear cells was observed. During septicaemia, organism might have localized in the kidneys, thereby producing the lesions. Similar changes reported in mice by Moshtagi et al., (2006) with presence of focal interstitial nephritis, focal areas of neutrophiles and lymphocytes in interstitial tissue and atrophy of tubules. Besides these, hyaline casts in tubules and cloudy swelling were recorded.

Lungs showed the focal interstitial pneumonia in sacrificed mice (Plate 5). However, more severe changes were observed in dead mice. Mild interstitial pneumonia, haemorrhage and cellular debris in bronchiole were observed in two dead mice. Similar changes were reported by Munder et al., (2005) in mice.

Lung sections revealed interstitial pneumonia, with infiltration of heterophils in the air capillaries and edema accumulating in the interparabronchial spaces in poultry. Similar results were reported by Crespo et al., (2013). 

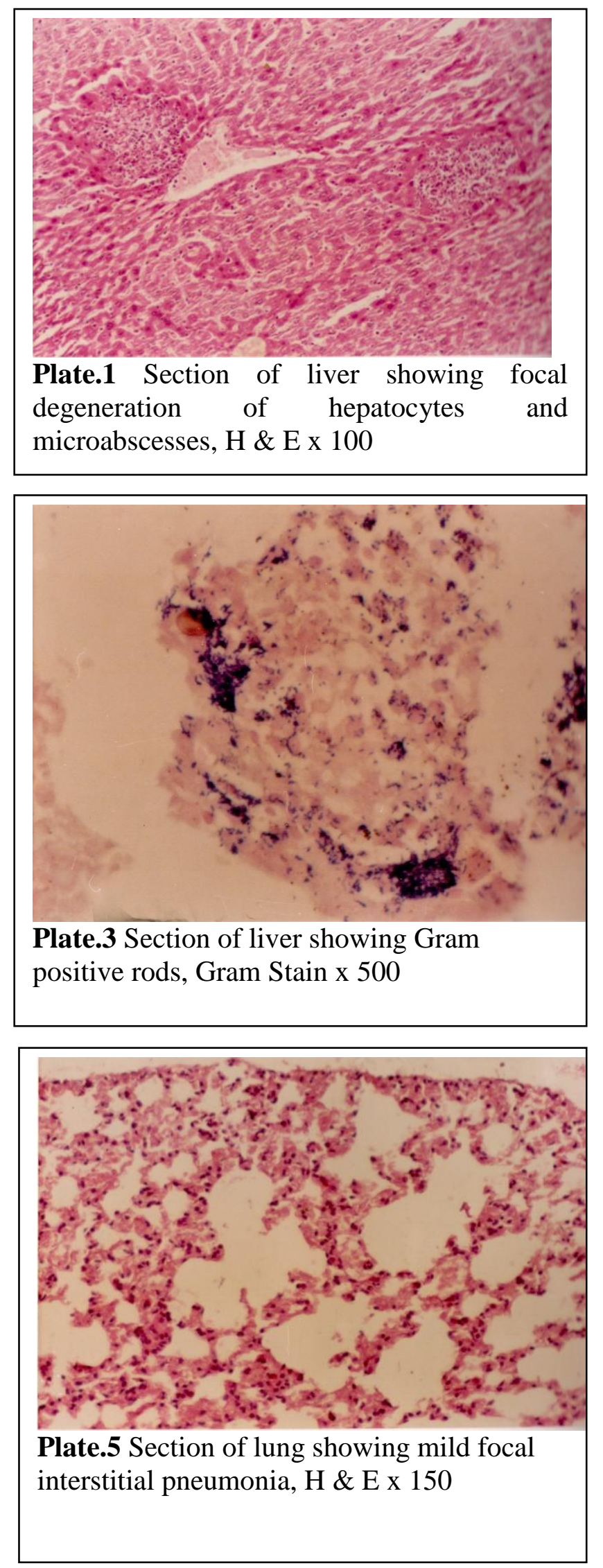

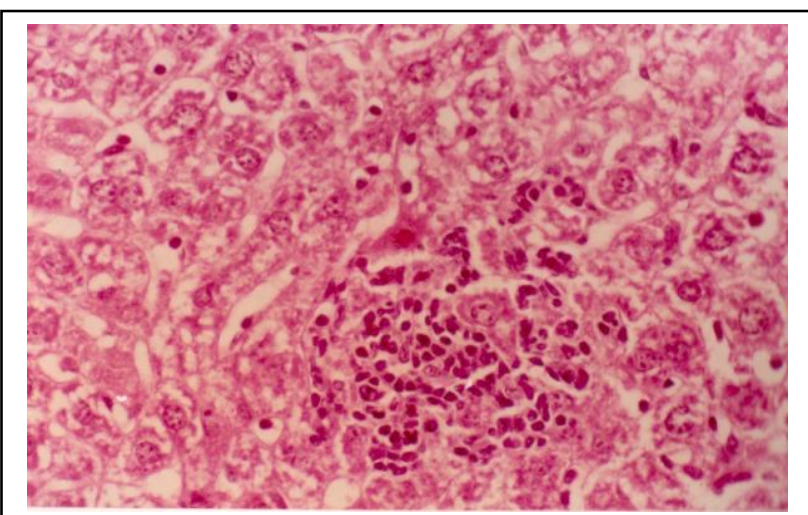

Plate.2 Section of liver showing moderate vacuolar degeneration of hepatocytes and small granuloma, H \& E x 300

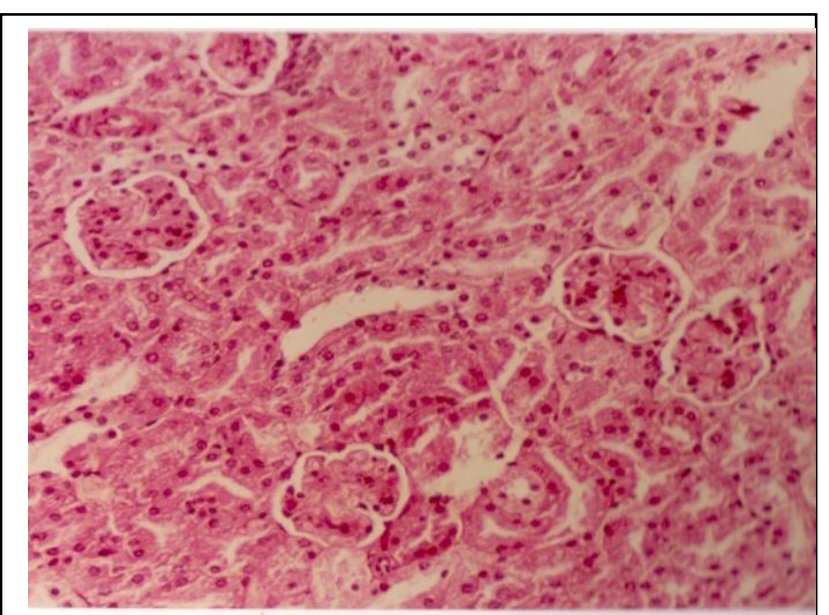

Plate.4 Section of kidney showing degeneration of cortical epithelial cells, $\mathrm{H}$ \& E x 150

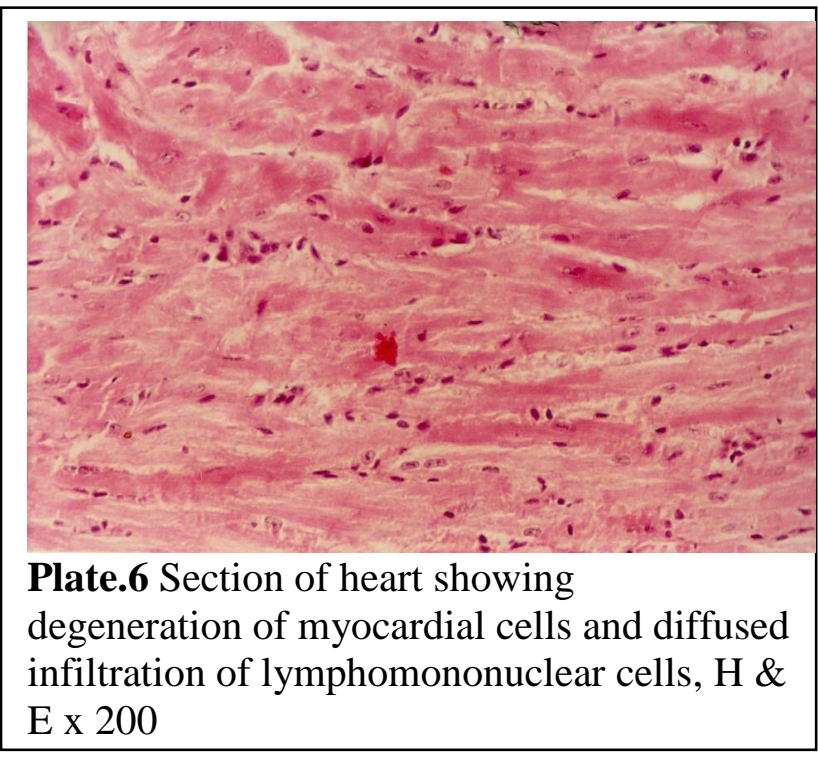



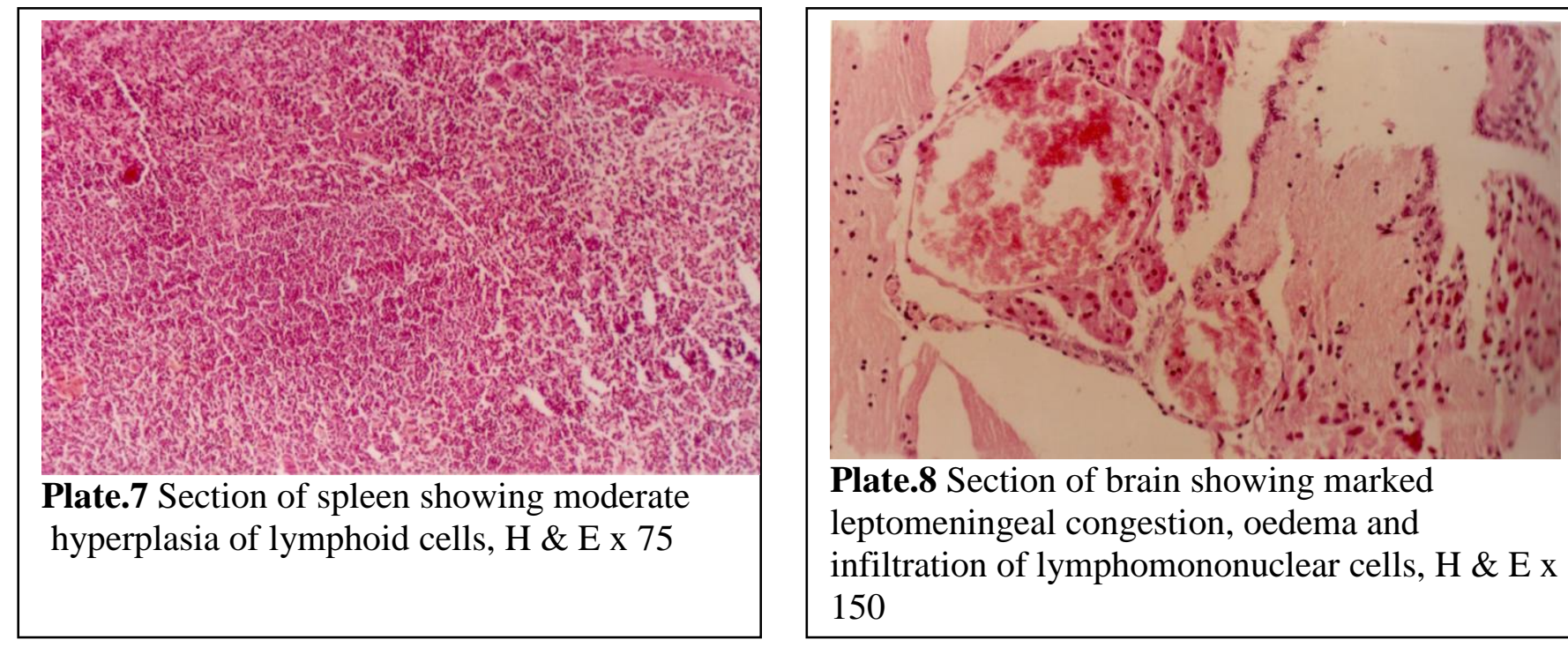

Plate.8 Section of brain showing marked leptomeningeal congestion, oedema and infiltration of lymphomononuclear cells, $\mathrm{H}$ \& E x 150

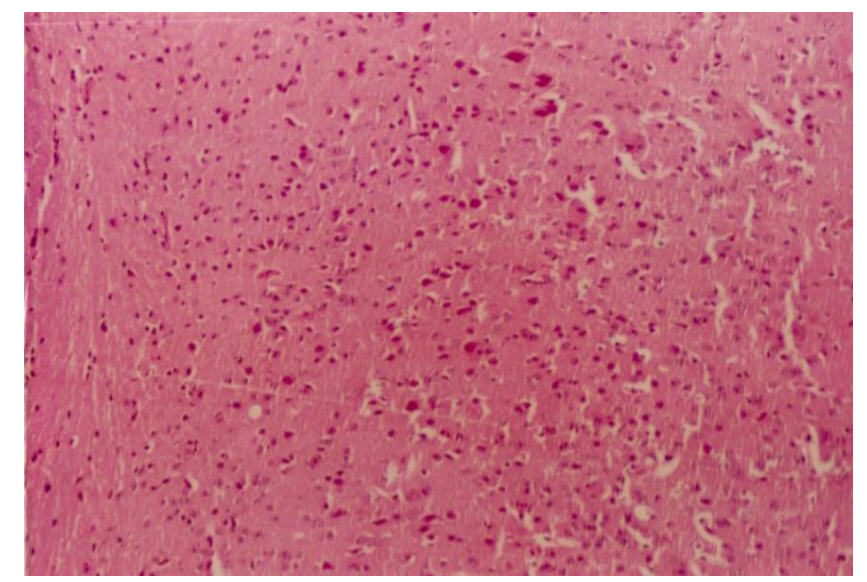

Plate.9 Section of brain showing marked gliosis in cerebrum, $\mathrm{H} \& \mathrm{E} \times 100$

Hyaline degeneration of cardiac muscles and mild focal lymphocytic myocarditis was observed in heart (Plate 6). The present findings are in agreement with those of Gray and Kallinger (1966). The most prominent lesion was extensive inflammation of the heart, consisted of lymphocytes, macrophages, numerous multinucleated giant cells, and occasional heterophils. The lumen of larger blood vessels contained numerous large lymphocytes and scattered heterophils in poultry (Crespo, et al., 2013).
Section of spleen showed moderate hyperplasia of lymphoid tissue in the lymphoid follicles (Plate 7) and around PALS was observed. There was comparative reduction in red pulp mass. Our results were in corroboration with the findings of Miller and Burns (1970) after oral feeding of mice with L. monocytogenes. It was inferred that histological lesions generally may be similar irrespective of route of infection. There was lymphocyte depletion and necrosis of lymphocytes in white pulp of spleen of the 
infected mice as was recorded by Moshtagi et al., (2006).

Histological changes observed in the brain included marked leptomeningeal congestion, edema, and infiltration of lymphomononuclear cells (Plate 8). Neuronal degeneration characterized by marked gliosis (Plate 9) and perivascular cuffing (Plate 10) was observed in cerebrum. In some mice gliosis led to formation of glial nodules. Our findings are in agreement with those of Gray and Kallinger (1966), Otter and Blackmore (1989) and (Boland et al., 2001) in the brain of sheep infected with $L$. monocytogenes. Moshtagi et al., (2006) observed microabcesses and necrosis of neurons, which was characterized by satellosis and neurophagia in mice.

Listeria monocytogenes isolates were intraperitonially administered to the mice to evaluate the pathomorphological effects in various organs of the infected mice. Seven groups of mice each comprising of three mice, were administered inocula prepared from seven isolates of $L$. monocytogenes, administering one isolate into one group and observed for 10 days. The pathomorphological effects in various organs infected with listeriosis in mice were evaluated on the basis of gross and histopathological changes. Immediately after the sacrifice of mice, systematic necropsy examination of all the visceral and immune organs was thoroughly conducted for any visible pathomorphological alteration. After thorough gross examination, small representative pieces of less than $5 \mathrm{~mm}$ thickness from respective organs were collected in 10 per cent neutral buffered formalin and processed routinely for histopathological examination. Prominent gross lesions included moderate to severe focal hepatic necrosis characteristic of listeric septicaemia. In some cases, brain and spleen were congested. No significant gross lesions were observed in heart, lungs and kidneys. Listeria monocytogenes was isolated from liver, spleen and brain of mice that died.

Histopathological examination revealed more severe changes in liver and included microabscesses with degenerated and intact neutrophils and mild infiltration of mononuclear cell. Section of kidneys of infected mice revealed mild focal vacuolar degeneration cortical epithelial cells and subcapsular infiltration of mononuclear cells was observed. Lungs showed the focal interstitial pneumonia in sacrified mice. Hyaline degeneration of cardiac muscles and mild focal lymphocytic myocarditis was observed in heart. A section of spleen showed moderate hyperplasia of lymphoid tissue in the lymphoid follicles and around PALS was observed. Changes observed in the brain included marked leptomeningeal congestion, edema, and infiltration of lymphomononuclear cells, neuronal degeneration characterized by marked gliosis and perivascular cuffing was observed in cerebrum.

\section{Acknowledgements}

The authors acknowledge Punjab Agricultural University for the technical assistance in carrying out this study.

\section{References}

Boland, J.A.V., Kuhn, M., Berche, P., Chakraborty, T., Bernal,G.D., Goebel, W., Bruno gonza'lez-zorn, B.G., Wehland, J. and Kreft, J. 2001. Listeria Pathogenesis and Molecular Virulence Determinants. Clin. Microbiol. Rev., 14 (1): 584-640

Condotta, S.A., Richer, M.J., Badovinac, V.P. and Harty, J.T. 2012. Probing CD8 T cell responses with Listeria 
monocytogenes infection. Adv. Immunol., 113, 51-80.

Conlan, J. C., and R. J. North. 1991. Neutrophil-mediated dissolution of infected host cells as a defense strategy against a facultative intracellular bacterium. J. Exp. Med. 174:741-744.

Conte, M.P., Petrone, G., Di Biase, A.M., Ammendolia, M.G., Superti, F. and Seganti, L. 2000. Acid tolerance in Listeria monocytogenes influences invasiveness of enterocyte like cells and macrophage-like cells. Microb. Pathog., 29: 137-144.

Crespo, R., Garner, M.M., Hopkins, S.G. and Shah, D.H. 2013. Outbreak of Listeria monocytogenes in an urban poultry flock. BMC. Vet. Res.., 9:204

Disson, O. 2009. Modeling human listeriosis in natural and genetically engineered animals. Nat. Protoc. 4, 799-810.

Enurah, L.U., Aboaba, O. O., Nwachukwu, S.C.U. and Nwosuh, C.I. 2013. Histopathological changes in the liver of mice challenged with Listeria monocytogenes in six zones of Nigeria. J. Exp. Biol. Agric. Sci., 1(5): 392-397

Gajendran, N. 2007. Regional IFNgamma expression is insufficient for efficacious control of food-borne bacterial pathogens at the gut epithelial barrier. Int. Immunol., 19, 1075-1081.

Gray, M.L. and Kallinger, A.H. 1966. Listeria monocytogenes and listeric infections. Bacteriol. Rev., 30: 309-382.

Hardy, J., Francis, K.P., Deboer, M., Chu, P., Gibbs, K. and Contag, C.H. 2004. Extracellular replication of Listeria monocytogenes in the murine gall bladder. Science., 303: 851-853.

Lecuit, M. 2007. Human listeriosis and animal models. Microb. Infect., 9:1216-1225.
Luna, L.G. 1968. Manual of histologic staining methods of the armed forces institute of pathology, 3rd edn. McGrawHill, New York.

Mclauchlin, J. and Low, J.C. 1994. Primary cutaneous listeriosis in adults: an occupational disease of veterinarians and farmers. Vet. Rec., 135: 615-617.

Melton-Witt, J.A., Rafelski, S.M., Portnoy, D.A. and Bakardjiev, A.I. 2012. Oral infection with signature-tagged Listeria monocytogenes reveals organ-specific growth and dissemination routes in guinea pigs. Infect. Immun., 80, 720-732.

Menudier, A., Bosiraud, C. and Jaen-Alber, N. 1991. Virulence of Listeria monocytogenes serovars and Listeria spp. in experimental infection of mice. Am. J. Clin. Path., 43: 248-250.

Miller, J.K. and Burns, J. 1970. Histopathology of Listeria monocytogenes after oral feeding to mice. Appl.. Microbiol., 19: 772-775.

Moshtagi, H., Arabi, M. and Karimi, I. 2006. Histopathology and pathogenesis of Listeriosis caused by Listeria monocytogenes isolated from raw milk im mice. Pak. J. Biol. Sci., 9(11) 2181-2183.

Otter, A. and Blackmore, W.F. 1989. Observations on the presence of Listeria monocytogenes in axons. Act. Microbiol. Hung., 36: 125-131.

Rocourt, J. 1999. The genus Listeria and Listeria monocytogenes: phylogenetic position, taxonomy, and identification, p. 1-20. In E. T. Ryser and E. H. Marth (ed.), Listeria, listeriosis, and food safety, 2nd ed. Marcel Dekker Inc., New York, N.Y.

Rogers, H.W. and E.R. Unanue. 1993. Neutrophils are involved in acute, non-specific resistance to Listeria monocytogenes in mice. Infect. Immun. 61:5090-5096. 
Rogers, H.W., M.P. Callery, B.D. and Unanue E.R. 1996. Listeria monocytogenes induces apoptosis of infected hepatocytes. J. Immunol. 156: 679684.

Takeuchi, K., Mytle, N., Lambert, S., Coleman, M., Doyle, M.P. and Smith, M.A. 2006. Comparison of Listeria monocytogene virulence in a mouse model. J Food Prot., 69:842-846.
Wing, E.J. and Gregory, S.H. 2002. Listeria monocytogenes: Clinical and experimental update. J. of Infect. Dis. 185:S18-S24.

Xiong, H., Kawamura, I., Nishibori, T. and Mitsuyama, M. 1994. Cytokine gene expression in mice at an early stage of infection with various strains of Listeria spp differing in virulence. Infect. Immun., 62:3649-3654.

\section{How to cite this article:}

Malik, M.A., J.K. Sharma, Moien Javaid, Maninder Singh and Raghubir Singh. 2017. Pathomorphological Alterations in Various Organs of Experimentally Induced Listeriosis in Mice. Int.J.Curr.Microbiol.App.Sci. 6(12): 1180-1188.

doi: https://doi.org/10.20546/ijcmas.2017.612.133 